\title{
Impact of Radiation-Induced Back-Channel Leakage and Back-Gate Bias on Drain Current Transients of Thin-Gate-Oxide Partially Depleted Silicon-On-Insulator n-channel Metal-Oxide-Semiconductor Field-Effect Transistors
}

\author{
Joan Marc RAFI', Abdelkarim MERCHA, Eddy SIMOEN, Kiyoteru HAYAMA \\ and Cor CLAEYS ${ }^{1}$ \\ IMEC, Kapeldreef 75, Leuven B-3001, Belgium \\ ${ }^{1}$ also at Electr. Eng. Dept., KU Leuven, Kasteelpark Arenberg 10, Leuven B-3001, Belgium
}

\section{Received:}

In this study, we analyze the impact of back-channel radiation-induced leakage and backgate bias on switch-off drain current transients of thin-gate-oxide partially depleted (PD) silicon-oninsulator (SOI) n-channel metal-oxide-semiconductor field-effect transistors (MOSFETs). The presence of radiation-induced positive trapped charges in the buried oxide after $60 \mathrm{MeV}$ proton irradiation is found to reduce the "switch-off" transient times for gate voltages above and below the front-gate threshold voltage for body-to-gate electron valence band tunnelling. An increase in steady-state drain current and an increase in the amplitude of weak inversion drain current transients are observed. A similar effect is observed when applying a positive bias to the back-gate, which is found to generate an "irradiation-like" subthreshold leakage. The observed switch-off drain current transient behavior is explained by taking into account an edge parasitic back-channel transient component, which is added to the conventional front-gate drain current transient.

KEYWORDS: buried oxide, drain current transients, floating-body effects, generation lifetime, proton irradiation, radiation effects, recombination lifetime, silicon-on-insulator (SOI) MOSFETs.

*Corresponding author. Present address: Centro Nacional de Microelectrónica (IMB-CNM-CSIC) Campus UAB, Bellaterra, 08193 Barcelona, Spain.

E-mail address: joanmarc.rafi@cnm.es 


\section{Introduction}

Silicon-on-insulator (SOI) metal-oxide-semiconductor field-effect transistors (MOSFETs) have several intrinsic potential advantages over their bulk Si counterparts as components to be operated in radiation harsh environments. ${ }^{1,2)}$ In particular, the thin semiconductor film provides better resistance against transient ionization effects such as single-event upsets or latch-up. ${ }^{3)}$ However, the thick SOI buried oxide introduces an additional constraint due to total ionizing dose charge trapping. ${ }^{3)}$ Moreover, owing to device integration requirements and intrinsic resistance constraints, no film contacts are generally provided in advanced SOI technologies. If body contacts are not present, so-called floating body effects (FBEs) arise, particularly in partially depleted (PD) SOI MOSFETs, leading to some detrimental effects on device performance. ${ }^{4,5)}$

As a consequence of FB operation, after switching "on" or "off" the front gate, there is no substrate current to quickly adjust the majority carrier density and equilibrium has to be reached through generation and recombination processes. Since early times, it is known that drain current $\left(\mathrm{I}_{\mathrm{D}}\right)$ transients are observed under these conditions ${ }^{6)}$ and their potential impact on circuit performance has been a matter of concern. ${ }^{7)}$ Originating from generation and recombination processes, $I_{D}$ transients can also be a valuable tool for assessing the quality of the starting material, process-induced defects or contamination. Different techniques have been proposed for PD or fully depleted (FD) SOI MOSFETs to extract the generation or recombination lifetimes from "switch-off" or "switch-on" $I_{D}$ transients, respectively. ${ }^{8-14)}$

Recently, with the marked decrease in front-gate-oxide thickness $\left(t_{\text {fox }}\right)$, a new type of FBE associated with gate-body direct tunnelling has been identified in linear operation [low drain voltage $\left(\mathrm{V}_{\mathrm{D}}\right)$ ] of SOI $\mathrm{n}$ - and p-channel MOSFETs. This new type of FBE has a similar 
influence on device and circuit operation as the classical impact-ionization-related "kink" effect. The main difference is that for thin gate oxides ( $t_{\text {fox }}$ as thin as $2-2.5 \mathrm{~nm}$ ), electron valence band $(\mathrm{EVB})$ tunnelling, occurring for a sufficiently large front-gate voltage $\left(\mathrm{V}_{\mathrm{FG}}\right)^{15)}$ supplies the necessary majority carriers to charge the film and forward-bias the source-body junction, inducing a "kink" in the linear $\mathrm{I}_{\mathrm{D}}-\mathrm{V}_{\mathrm{FG}}$ characteristics and a second peak in the derived transconductance. ${ }^{16,17)}$ Associated with this effect, an increase in low-frequency noise ${ }^{18,19)}$ and a change in $I_{D}$ transient shape ${ }^{16,17,20)}$ have also been reported. The presence of these gate-induced FBEs (GIFBEs), ${ }^{16)}$ leading to history and memory effects, could be a limitation for PD SOI CMOS circuit operation. ${ }^{21)}$

Although the continuous miniaturization process has implicitly led to radiationresistant front-gate oxides, with a thickness below the trapped-hole tunnelling limit, since the early times, there has been concern regarding total ionizing dose charge trapping in the buried oxides. ${ }^{22,23)}$ Studies have been carried out on SOI devices with a wide range of substrate qualities $^{24)}$ and, in a number of cases, a significant impact of buried oxide trapped charges on device front characteristics has been pointed out. ${ }^{22,25)}$

The increase in gate coupling associated with the decrease in semiconductor film thickness is expected to make SOI MOSFETs more sensitive to buried oxide charge trapping. ${ }^{26)}$ In this way, while an increase in leakage current in the subthreshold region is reported for PD SOI nMOSFETs, ${ }^{3)}$ which is normally associated with parasitic edge conduction in the case of LOCOS (local oxidation of silicon)-isolated devices, ${ }^{25,27-29)}$ a decrease in top-gate threshold voltage, due to gate coupling, is observed in fully depleted (FD) nMOSFETs. ${ }^{3,30)}$ 
In this study, we analyze the impact of back-channel radiation-induced leakage and back-gate bias on the switch-off drain current transients of thin-gate-oxide PD SOI nMOSFETs. The presence of radiation-induced positive trapped charges in the buried oxide after $60 \mathrm{MeV}$ proton irradiation is found to decrease the switch-off transient times for frontgate voltages above and below the front-gate threshold voltage for body-to-gate EVB tunnelling. An increase in steady-state drain current level and an increase in the amplitude of the weak inversion drain current transients are observed. A similar effect is obtained when applying a positive bias to the back-gate, which is found to generate an "irradiation-like" subthreshold leakage. The observed switch-off drain current transients behavior is explained by taking into account an edge parasitic back-channel transient component, which is added to the conventional front-gate drain current transient.

\section{Devices and Experimental Procedure}

The PD SOI MOSFETs used in this study were fabricated in a $0.1 \mu \mathrm{m}$ CMOS process using a PELOX (polysilicon-encapsulated LOCOS) isolation scheme, a $2.5 \mathrm{~nm}\left(\mathrm{t}_{\text {fox }}\right)$ nitrided gate oxide (NO), a $150 \mathrm{~nm}$ polysilicon gate and $80 \mathrm{~nm}$ nitride spacers. Processing was performed on 200-mm-diameter Unibond wafers, resulting in a final film thickness $\left(\mathrm{t}_{\mathrm{si}}\right)$ of 100 $\mathrm{nm}$. The buried oxide thickness ( $\mathrm{t}_{\mathrm{box}}$ ) was $400 \mathrm{~nm}$. The devices received halo implantation, in order to control the short-channel effects.

The studied MOSFETs have a common gate and source configuration with separate drain pads. There is no film contact. N- and p-channel transistors with polysilicon gate lengths (L) and widths (W) ranging from 0.08 to $10 \mu \mathrm{m}$ and 0.2 to $10 \mu \mathrm{m}$, respectively, were studied. 
However, in order to avoid short and narrow device geometry effects on $I_{D}$ transients ${ }^{16,17)}$, only results from long $(\mathrm{L}=10 \mu \mathrm{m})$ and wide $(\mathrm{W}=10 \mu \mathrm{m})$ transistors are reported here. Moreover, the results shown in this study focus on the n-channel devices, which showed radiation-induced degradation after $60 \mathrm{MeV}$ proton exposure.

In order to enable biased irradiation, the chips were mounted in 24-pin dual-in-line packages and were subjected to two consecutive (40 days in between) $60 \mathrm{MeV}$ proton irradiations at the Cyclone cyclotron facility (Louvain-la-Neuve, Belgium), each one up to a fluence of $10^{11}$ protons $/ \mathrm{cm}^{2}$, which corresponds to a dose of approximately $13.5 \mathrm{krd}(\mathrm{Si})$, suitable for space applications such as radiation-hardness assessment. ${ }^{31)}$ In addition, unbiased irradiations on diced chips were also performed, yielding qualitatively similar results. ${ }^{32,33)}$

During the irradiation, the gates of all the mounted transistors (nMOSFETs and pMOSFETs) were biased at a positive bias corresponding to the power supply voltage for this technology $(+1.5 \mathrm{~V})$, while all the other terminals were grounded.

All current-voltage measurements and drain current transients were measured using an HP-4156 Parameter Analyzer. During a conventional weak inversion single-gate "switch-off" experiment, the front gate was switched at $\mathrm{t}=0 \mathrm{~s}$ from an 'on' gate bias ( $\mathrm{V}_{\mathrm{FG}}$ on $)$ above the front-gate threshold voltage $\left(\mathrm{V}_{\mathrm{Tf}}\right)$ to an 'off' gate bias $\left(\mathrm{V}_{\mathrm{FG}}\right.$ off $)$ in the subthreshold regime. Care was taken with the duration of the 'on' bias level, as well as for the conditions between the two transient measurements, so that there were no device history (memory) effects. Unless, the contrary is indicated, the drain bias was kept in the linear operating regime $\left(\left|V_{D}\right|=\right.$ $25 \mathrm{mV}$ ) for all measurements. All experiments were carried out in a controlled-temperature room with a lightproof and electrically shielded setup. 


\section{Experimental Results and Discussion}

\subsection{Radiation-induced back-channel leakage and $V_{B G}$ effect on $I_{D^{-}} V_{F G}$ characteristics}

Figure 1(a) shows typical $I_{D}$ and transconductance $\left(g_{m}\right)$ vs front-gate voltage $\left(V_{F G}\right)$ characteristics measured at two different back-gate biases $\left(\mathrm{V}_{\mathrm{BG}}=0 \mathrm{~V}\right.$ and $\left.-20 \mathrm{~V}\right)$ for a $\mathrm{PD}$ SOI nMOSFET subjected to $2 \cdot 10^{11}$ protons $/ \mathrm{cm}^{2}$ irradiation. ${ }^{32)}$ In the same figure, characteristics corresponding to a nonirradiated nMOSFET measured at different $\mathrm{V}_{\mathrm{BG}}$ values ranging from -20 to $20 \mathrm{~V}$ are also shown. A clear increase in subthreshold leakage current is observed after irradiation of the nMOSFETs measured at $\mathrm{V}_{\mathrm{BG}}=0 \mathrm{~V}$. Moreover, this radiationinduced $\mathrm{I}_{\mathrm{D}}$ subthreshold leakage has been found to decrease when applying a negative $\mathrm{V}_{\mathrm{BG}}$. In this way, the characteristics of irradiated devices with sufficiently negative $V_{B G}$ are found to fit with those before irradiation [Fig. 1(a)].

Furthermore, as shown in Fig. 1(a), the application of a positive bias to the back gate has been found to result in the generation of "irradiation-like" subthreshold conduction. In this way, there is a strong similarity between the $I_{D}-V_{F G}$ characteristics of irradiated nMOSFETs measured at $\mathrm{V}_{\mathrm{BG}}=0 \mathrm{~V}$ and the characteristics measured on nonirradiated transistors at a sufficiently positive $\mathrm{V}_{\mathrm{BG}}$. In contrast, only a small radiation-induced degradation has been occasionally observed in the GIDL (gate-induced drain leakage) ${ }^{34)}$ region for p-channel MOSFETs [Fig. 1(b)].

An important feature of the characteristics of these thin-gate-oxide PD SOI MOSFETs is the occurrence of a second peak in the transconductance for a $\left|\mathrm{V}_{\mathrm{FG}}\right|$ of approximately $1.2 \mathrm{~V}$ [Fig. 1 (a) and (b)]. This second $g_{m}$ peak is due to the injection of majority carriers in the floating body by EVB tunnelling, ${ }^{16,17)}$ which is quite analogous to the classical impact- 
ionization-related kink effect. The main difference is that the excess majority carriers are introduced into the film by gate-body direct tunnelling when $\mathrm{V}_{\mathrm{FG}}$ surpasses the threshold voltage for EVB tunnelling. Consequently, it is observed for small drain biases $\left(\mathrm{V}_{\mathrm{D}}\right)$ and is, therefore, present in the ohmic operation regime.

Neither the radiation-induced back-channel parasitic conduction nor the leakage obtained by applying a positive $\mathrm{V}_{\mathrm{BG}}$ have been found to affect the portion of the characteristics above the front-gate threshold voltage and, in particular, the magnitude or the position of the EVB-induced second peak of $\mathrm{g}_{\mathrm{m}}{ }^{32)}$

By measuring the back-gate characteristics $\left(\mathrm{I}_{\mathrm{D}}-\mathrm{V}_{\mathrm{BG}}\right)$, the observed degradation has been found to be associated with a positive back-gate threshold voltage shift $\left(\Delta \mathrm{V}_{\mathrm{Tb}} \approx 14 \mathrm{~V}\right.$, Fig 1(a)) caused by radiation-induced hole trapping in the thick buried oxide. The effective density of trapped holes $\left[\mathrm{N}_{\mathrm{otb}} \approx \Delta \mathrm{V}_{\mathrm{Tb}} /\left(\varepsilon_{\mathrm{ox}} / \mathrm{t}_{\mathrm{box}}\right)\right]$ has been estimated to be approximately $7.5 \cdot 10^{11}$ charges $/ \mathrm{cm}^{2}$ for devices biased during the irradiation, whereas this has been found to be approximately three times smaller in the case of devices not biased during the irradiation. ${ }^{32)}$ Evidently, no such effect is expected for the pMOSFETs, in which the back channel becomes more accumulated upon positive charging of the buried oxide, which on the other hand may be responsible for the occasionally small current increase in the pMOSFETs GIDL region [Fig. 1(b)].

In order to distinguish between parasitic conduction due to the inversion of the back channel or that mainly concentrated along the edges between the buried oxide and the PELOX field isolation, ${ }^{5,29)}$ the $\mathrm{I}_{\mathrm{D}}$ subthreshold leakage dependence on gate width was investigated. The results showed no dependence on $\mathrm{W}$ of the subthreshold leakage current up to values of 
approximately $\mathrm{V}_{\mathrm{BG}}=80 \mathrm{~V}$, where the switch-on of an additional back-channel conduction path was noted. This additional conduction at very high $\mathrm{V}_{\mathrm{BG}}$ is found to be dependent on $\mathrm{W}$ and is attributed to the creation of the inversion back-channel layer. In this way, the conduction observed for $\mathrm{V}_{\mathrm{BG}}$ voltages up to approximately $80 \mathrm{~V}$, which is independent of $\mathrm{W}$, is associated with the parasitic conduction along the edges between the buried oxide and the PELOX field isolation. ${ }^{25,28,35)}$ Although shallow trench isolation (STI) provides benefits for more scaled technologies, enabling a smaller isolation spacing than with PELOX, STI can also give rise to a similar subthreshold conduction after irradiation, when not properly optimized. ${ }^{36,37)}$

\section{2 "Switch-off" I I transients in thin-gate-oxide PD SOI MOSFETs and lifetime extraction}

In a conventional weak inversion single gate switch-off experiment, $\mid \mathrm{V}_{\mathrm{FG}}$ on $\mid$ is taken above $\mathrm{V}_{\mathrm{Tf}}\left(\mathrm{V}_{\mathrm{Tf}} \approx 0.35 \mathrm{~V}\right.$ for our long NMOSFETs $)$, whereas $\mid \mathrm{V}_{\mathrm{FG}}$ off $\mid$ is taken in the subthreshold regime. After switching-off the devices from $\left|\mathrm{V}_{\mathrm{FG} \text { on }}\right|=0.7 \mathrm{~V}$ to $\left|\mathrm{V}_{\mathrm{FG} \text { off }}\right|=0.1 \mathrm{~V}$, an increase in drain current $\left|I_{D}(t)\right|$ is observed for 20 - 30 s until the $I_{D}$ steady-state value $\left(I_{D}(t=\infty)\right)$ is reached [Figs. 2(a) and 2(b)].

It has been shown that for a fixed temperature, the measured $I_{D}$ transient time $T_{0}$ [defined as the time to reach $90 \%$ of $I_{D}(t=\infty)$ ] can be used to extract the effective film generation lifetime ( $\tau_{\text {geff }}$ ) of PD SOI MOSFETs, by the approximated linear relationship ${ }^{13)}$

$$
\tau_{\text {geff }} \approx \frac{\mathrm{T}_{0}}{\mathrm{~K}}
$$

with $\mathrm{K}$ a technology and temperature-dependent factor, that under our experimental conditions and for devices with a $2.5-\mathrm{nm}$-thick gate oxide and a $5.5 \times 10^{17} \mathrm{~cm}^{-3}$ average film doping concentration, is easily calculated to be approximately $120 \times 10^{6} .{ }^{13,38}$ ) 
Using this procedure, a $\tau_{\text {geff }}$ of approximately $0.2 \mu$ s has been extracted for the devices under study in this work, these values being in the range of the data published in the literature for similar high-quality SOI materials and conditions. ${ }^{4,12-14,39)}$ In fact, the absolute lifetime value is not so important, but it arises as a useful parameter for comparison between different starting materials, processings or irradiation conditions.

An interesting feature associated with the EVB tunnelling phenomenon giving rise to the second peak in $g_{m}$ [Figs. 1(a) and 1(b)] is the fact that the switch-off transients are found to change their shape from undershoot to overshoot when $V_{F G}$ on is above the $V_{F G}$ threshold for EVB tunnelling $\left[\mid \mathrm{V}_{\mathrm{FG}}\right.$ on $\mid=1.5 \mathrm{~V}$ data in Figs. 2(a) and 2(b)]. In fact, this probes the injection of majority carriers into the substrate, ${ }^{16,17)}$ which disappear after switching off the device. The shape of these transients has been found to fit well with conventional (EVB-free) switch-on-type transients, ${ }^{40)}$ which enable the extraction of the majority carrier recombination lifetime. ${ }^{12)}$ Since carrier recombination is usually faster than generation, ${ }^{12,41)}$ the transients in the EVB tunnelling regime $\left[\mid \mathrm{V}_{\mathrm{FG}}\right.$ on $\mid=1.5 \mathrm{~V}$ data in Figs. 2(a) and 2(b)], are faster compared with the normal switch-off ones [ $\left|\mathrm{V}_{\mathrm{FG} \text { on }}=0.7 \mathrm{~V}\right|$ data in Figs. 2(a) and 2(b)].

\subsection{Zerbst-type lifetime extraction method}

The above generation lifetime measurement method, based on the relationship between the $I_{D}$ transient time $\left(T_{0}\right)$ and the film $\tau_{\text {geff }}$ [eq. (1)] has been successfully confirmed to be effective for PD SOI MOSFETs ${ }^{13)}$ compared with a well-established dual-gate Zerbsttype technique previously published. ${ }^{9)}$ In a dual-gate experiment, one of the two gates (usually the back gate) is switched off from depletion to accumulation, while the other is kept in strong inversion. Very close $\tau_{\text {geff }}$ values have been extracted with the two methods, 
allowing to conclude that the surface component is not playing a determinant role under these conditions. $^{13)}$

The dual-gate technique is based on the equation that describes the time evolution of minority and majority carriers at the front and back gates, respectively ${ }^{9,42}$ )

$$
\frac{1}{\mathrm{qn}_{\mathrm{i}}}\left(\frac{\mathrm{dQ}_{\mathrm{depf}}(\mathrm{t})}{\mathrm{dt}}+\frac{\mathrm{dQ}_{\mathrm{accb}}(\mathrm{t})}{\mathrm{dt}}\right)=\frac{\mathrm{W}(\mathrm{t})-\mathrm{W}_{\infty}}{\tau_{\mathrm{geff}}}+\mathrm{S}_{\text {eff }}
$$

Here, $\mathrm{q}$ is the electron charge, $\mathrm{n}_{\mathrm{i}}$ is the intrinsic carrier concentration, $\mathrm{Q}_{\text {depf }}(\mathrm{t})$ and $\mathrm{Q}_{\text {accb }}(\mathrm{t})$ are the front-gate depletion and back-gate accumulation charges, $\mathrm{W}$ is the depletion region depth and $\tau_{\text {geff }}$ and $S_{\text {eff }}$ are the effective generation lifetime and surface generation velocity, respectively.

The above formula [eq. (2)] has been found to also be appropriate for describing $I_{D}$ transients in the weak inversion regime, i.e., with $\mathrm{V}_{\mathrm{FG}}$ below $\mathrm{V}_{\mathrm{Tf}}^{42)}$ or even to describe singlegate $I_{D}$ transients observed when switching off the front gate (from $V_{F G}>V_{T f}$ to $V_{F G}<V_{T f}$ ) while keeping the back gate grounded, ${ }^{39)}$ which is very suitable in our case to also evaluate the buried oxide interface quality. ${ }^{43)}$

With conventional expressions for $\mathrm{I}_{\mathrm{D}}$ and the involved charges corresponding to PD SOI devices in the weak inversion regime, the $I_{D}$ transient formula of eq. (2) is found to be described by eq. (3) ${ }^{39,42)}$

$$
\underbrace{\frac{\mathrm{C}_{\text {fox }}}{\mathrm{qn}_{\mathrm{i}} \beta} \frac{1}{\mathrm{I}_{\mathrm{D}}(\mathrm{t})} \frac{\mathrm{dI}_{\mathrm{D}}(\mathrm{t})}{\mathrm{dt}}}_{\text {LHS }}=\underbrace{\frac{\mathrm{C}_{\text {fox }}}{\mathrm{qN}_{\mathrm{a}} \beta} \operatorname{Ln}\left(\frac{\mathrm{I}_{\mathrm{D}}(\mathrm{t}=\infty)}{\mathrm{I}_{\mathrm{D}}(\mathrm{t})}\right)}_{\text {RHS }} \frac{1}{\tau_{\mathrm{geff}}}+\mathrm{S}_{\text {eff }}
$$


Here, $\beta \equiv \mathrm{q} / \mathrm{kT}$ is the inverse of the thermal voltage, $\mathrm{k}$ is the Boltzmann constant, $\mathrm{N}_{\mathrm{a}}$ is the film doping concentration and $\mathrm{C}_{\text {fox }} \equiv \varepsilon_{\text {ox }} / \mathrm{t}_{\text {fox }}$ is the front-gate oxide capacitance density.

Plotting the left-hand side $(\operatorname{LHS}(t))$ of eq. (3) as a function of the right-hand side $(\mathrm{RHS}(\mathrm{t}))$, the effective generation lifetime $\left(\tau_{\text {geff }}\right)$ and the surface generation velocity $\left(\mathrm{S}_{\text {eff }}\right)$ can be determined from the slope and the intercept with the vertical axis, respectively. As the front-surface potential is not pinned in the case of a weak inversion transient, some small deviation from eq. (3), associated with time-dependent $\mathrm{S}_{\text {eff, }}$ can sometimes be appreciated, particularly at the beginning of the transient. ${ }^{42,44)}$

In order to better analyze the experimental $I_{D}$ transients, this $\tau_{\text {geff }}$ extraction procedure was applied to our measurements. In this way, Fig. 3 shows the obtained LHS vs RHS plots (eq. (3)) corresponding to the "switch-off" (from $V_{F G \text { on }}=0.7 \mathrm{~V}$ to $V_{F G \text { off }}=0.1 \mathrm{~V}$ ) $\mathrm{I}_{\mathrm{D}}$ transients measured for an $\mathrm{L}=\mathrm{W}=10 \mu \mathrm{m}$ nMOSFET biased under different $\mathrm{V}_{\mathrm{D}}$ conditions. When extending this analysis to increased $V_{D}$ values, $\tau_{\text {geff }}$ is found to be markedly decreased, which can be associated with carrier generation in the increased space-charge region near the drain. $^{38,45)}$ Naturally, for high $\mathrm{V}_{\mathrm{D}}$ values (above $\sim 0.75 \mathrm{~V}$ ) sub-band gap impact ionisation can start introducing majority carriers into the film, ${ }^{46)}$ which makes the transients faster and difficult to measure with a parameter analyzer. The corresponding $\tau_{\text {geff }}$ values extracted from eq. (3) are shown in the inset of Fig. 3 as a function of $1 / V_{D}$. The $\tau_{\text {geff }}$ values extracted from the $I_{D}$ transient time $T_{0}$ [defined at $90 \%$ of $I_{D}(t=\infty)$, following eq. (1)] are also given for comparison. ${ }^{38)}$ A reasonable agreement between the two $\tau_{\text {geff }}$ extraction methods is found, enabling the estimation of effective film generation lifetime in the range of 0.2-0.3 $\mu$ s. 
In spite of the different techniques published in the literature to extract the generation and recombination lifetimes from $I_{D}$ transients, there are only few studies discussing their applicability to the investigation of radiation effects. ${ }^{11,47)}$ Moreover, these only concentrate on the study of the generation lifetime and, to our best knowledge, no results including the recombination lifetime degradation have been reported. Under their experimental conditions, these works pointed to a reduction in bulk generation lifetime, together with an increase in surface generation velocity after irradiation. ${ }^{11,47)}$

In order to investigate the effects of radiation on SOI film generation and recombination lifetimes, switch-off $I_{D}$ transients were measured on the $n$-channel and $p$ channel MOSFETs before and after irradiation, using front-gate voltages above and below the threshold voltage for body-to-gate EVB tunnelling.

As can be seen from $\mathrm{V}_{\mathrm{FG} \text { on }}=0.7 \mathrm{~V}$ results in Fig. 2(a), the nMOSFET's conventional switch-off transients become much faster after irradiation, ${ }^{32,38)}$ which could point to a

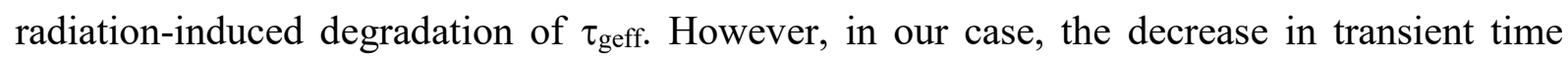
should not be directly attributed to a decrease in film lifetime, but rather associated with the radiation-induced increase in subthreshold leakage current [Fig. 1(a)]. This is supported by the fact that the $I_{D}$ transients measured for nonirradiated nMOSFETs at $V_{B G}=14 \mathrm{~V}$, which give rise to "irradiation-like" back-channel parasitic conduction [Fig. 1(a)], are found to fit very well with those corresponding to the irradiated devices measured at $\mathrm{V}_{\mathrm{BG}}=0 \mathrm{~V}$ [Fig. 2(b)]. Furthermore, as shown in Fig. 2(b), the transients measured on the p-channel devices, with no radiation-induced leakage [Fig. 1(b)], do not show any significant change after irradiation. 
As shown in the Fig. 2(a) for $\mathrm{V}_{\mathrm{FG}}$ on $=1.5 \mathrm{~V}$, irradiation also seems to speed up in a similar way the recombination of the majority carriers introduced into the film during the $V_{F G}$ ${ }_{\mathrm{on}}=1.5 \mathrm{~V}$ step. However, this apparent faster hole removal in the n-channel devices may be again associated with the radiation-induced subthreshold leakage and this possibility will be analyzed in the following paragraphs.

\section{$3.5 V_{B G}$ and "switch-off" I $I_{D}$ transients}

In order to investigate the impact of back-channel leakage on $I_{D}$ transients, switch-off measurements were performed on irradiated and nonirradiated nMOSFETs applying different $\mathrm{V}_{\mathrm{BG}}$ biases. It was envisaged that different back-channel conditions could play an important role in the $\mathrm{I}_{\mathrm{D}}$ transient behavior (steady-state current and transient time). In the past, longer transient times were observed with the back gate in weak accumulation ${ }^{45)}$ that was attributed to a reduction of some generation component associated with the back surface or device edges. ${ }^{45}$ Figures 4(a) and 4(b) show the obtained results for a nonirradiated transistor after switching off its front gate from $\mathrm{V}_{\mathrm{FG} \text { on }}=0.7 \mathrm{~V}$ to $\mathrm{V}_{\mathrm{FG} \text { off }}=0.1 \mathrm{~V}$.

As observed in Fig. 4(a), it is found that the steady-state $I_{D}\left[I_{D}(t=\infty)\right]$ is markedly increased when applying $\mathrm{V}_{\mathrm{BG}}$ values above the back-gate threshold voltage $\left(\mathrm{V}_{\mathrm{Tb}}\right)$, which is approximately $6 \mathrm{~V}$ for these long and wide $\mathrm{n}$-channel transistors. ${ }^{32)}$ The activation of this back-channel conduction is found to be responsible for the faster $I_{D}$ normalized transients observed in irradiated devices [Fig. 2(a)], as well as for the nonirradiated ones with sufficiently positive $\mathrm{V}_{\mathrm{BG}}$ [Fig. 4(b)]. On the other hand, as expected, the application of a backchannel accumulation bias $\left(\mathrm{V}_{\mathrm{BG}}<0\right)$ to the nMOSFETs has been found to result in small 
changes in $I_{D}(t=\infty)$. However, for sufficiently negative $V_{B G}(<-5 V)$, the transients get considerably faster and their amplitude decreases as well [Figs. 4(a) and 4(b)].

In order to better analyze the impact of $\mathrm{V}_{\mathrm{BG}}$ on the transients behavior, Fig. 5 shows the extracted $I_{D}$ transient times, defined as the times to reach either, 90\% (undershoot) or $110 \%$ (overshoot) of $\mathrm{I}_{\mathrm{D}}(\mathrm{t}=\infty)$, measured for irradiated and nonirradiated $\mathrm{L}=\mathrm{W}=10 \mu \mathrm{m}$ nMOSFETs after switching off their front gate from $\mathrm{V}_{\mathrm{FG} \text { on }}=0.7 \mathrm{~V}$ to $\mathrm{V}_{\mathrm{FG} \text { off }}=0.1 \mathrm{~V}$ and from $\mathrm{V}_{\mathrm{FG} \text { on }}=1.5 \mathrm{~V}$ to $\mathrm{V}_{\mathrm{FG} \text { off }}=0.1 \mathrm{~V}$, respectively.

As clearly seen, the $I_{D}$ transient times behave in a $V_{B G}$-bell-shaped way, with a maximum at approximately $\mathrm{V}_{\mathrm{BG}}=-5 \mathrm{~V}$. In this way, as commented on the results shown in Figs. 2(a) and 2(b), both types of transients (overshoots and undershoots) are found to be significantly faster after irradiation or when a sufficiently positive $V_{B G}$ is applied. In this case, the decrease in transient time is mainly attributed to the increased level of conduction due to the back-edge-channel leakage and the effect of the normalization, but not to the duration of the $I_{D}$ excursion itself [Figs 4(a) and 4(b)].

On the other hand, the impact of back gate in strong accumulation $\left(\mathrm{V}_{\mathrm{BG}}<\sim-10 \mathrm{~V}\right)$ is found to importantly decrease the transient time without introducing significant changes in steady-state drain current $\left[\mathrm{I}_{\mathrm{D}}(\mathrm{t}=\infty)\right]$, thus, in this case, there is a clear decrease in film effective lifetime. This is explained by an electric-field-enhanced generation similar to that of the conventional front-gate GIDL mechanism, ${ }^{34)}$ but occurring in this case in the accumulated back channel. Even at low $V_{D}$, the drain junction introduces majority carriers into the film when the film surface is strongly accumulated, thus reducing the transient time. In fact, some results in this direction were already envisaged in some early $I_{D}$ transient studies. ${ }^{48,49)}$ This is 
further supported by the exponential decrease in transient time with increasing negative $V_{B G}$ biases (Fig. 5), which is associated with the GIDL exponential behavior, for which the backgate-to-drain voltage drop and BOX thickness determine the relevant surface electric field. ${ }^{34)}$

A final comment regarding Fig. 5 results corresponds to the different behavior observed after irradiation on both sides $\left(\mathrm{V}_{\mathrm{BG}}<0\right.$ and $\left.\mathrm{V}_{\mathrm{BG}}>0\right)$ of the bell-shaped transient time vs $V_{B G}$ curves. In this way, whilst a clear shift towards lower $V_{B G}$ values is observed for the positive $\mathrm{V}_{\mathrm{BG}}$ branch, which is associated with the radiation-induced back-gate threshold voltage shift $\left(\Delta \mathrm{V}_{\mathrm{Tb}}\right)$, no clear change is observed for the negative $\mathrm{V}_{\mathrm{BG}}$ part. This is due to the fact that for this case of accumulation back-gate bias, the relevant junction to back-channel field giving rise to the BGIDL mechanism is not affected by the radiation-induced buried oxide charge trapping, because of the existing full overlap between the buried oxide and the source and drain junctions.

In order to better illustrate the impact of $\mathrm{V}_{\mathrm{BG}}$ on transients behavior, eq. (3) was also applied to the $I_{D}$ transients of irradiated and nonirradiated nMOSFETs. In this way, Figs. 6(a) and 6(b) show the obtained LHS vs RHS plots. From the figures, the impact of either, irradiation or accumulation $\mathrm{V}_{\mathrm{BG}}$ is found to significantly reduce $\tau_{\text {geff }}$ [increase in LHS vs RHS slope in eq. (3)].

\section{6 "Switch-off" $I_{D}$ transients and effective gate voltage overdrives ( $\Delta V_{F G}$ eff and $\left.\Delta V_{B G \text { eff }}\right)$}

As derived from Fig. 4(a), a very interesting feature of the $I_{D}$ transients measured under different $\mathrm{V}_{\mathrm{BG}}$ conditions is the fact that their amplitude is found to significantly increase for $V_{B G}$ values above $V_{T b}$. In this way, Fig. 7 shows the magnitude of the $I_{D}$ 
excursion $\left(\mathrm{I}_{\mathrm{D}}(\mathrm{t}=0)-\mathrm{I}_{\mathrm{D}}(\mathrm{t}=\infty)\right)$ for irradiated and nonirradiated nMOSFETs measured under different $V_{B G}$ conditions. From the figure, the appearance of a step in $I_{D}(t=0)-I_{D}(t=\infty)$ is found for $\mathrm{V}_{\mathrm{BG}}$ values at approximately $\mathrm{V}_{\mathrm{Tb}}$, in which the back-channel parasitic conduction starts flowing along the field isolation/buried oxide edges.

In view of Fig. 7 results, one has to disregard the possibility of having only a front gate $\mathrm{I}_{\mathrm{D}}$ transient for $\mathrm{V}_{\mathrm{BG}}>\mathrm{V}_{\mathrm{Tb}}$ conditions. If this was the case, an increase in $\mathrm{V}_{\mathrm{BG}}$ should be accompanied by an increase in steady-state $I_{D}\left[I_{D}(t=\infty)\right]$ but keeping a fixed amplitude for $I_{D}$ transients, i.e., with $I_{D}(t=0)-I_{D}(t=\infty)$ being constant. As this is not the case in Fig. 4(a) and Fig. 7, and we have found the existence of back-channel conduction, we can assume that under $\mathrm{V}_{\mathrm{BG}}>\mathrm{V}_{\mathrm{Tb}}$ conditions the measured $\mathrm{I}_{\mathrm{D}}$ transients are originated from both front- and back-edgechannel conduction.

In order to explain the observed transient behavior under $\mathrm{V}_{\mathrm{BG}}>\mathrm{V}_{\mathrm{Tb}}$ conditions, one may think to replace the original $d Q_{a c c b}(t) / d t$ factor in eq. (2) by a new $d Q_{\operatorname{deplb}}(t) / d t$ factor that would take into account the change in the depletion charge associated with the back channel. However, owing to $t_{\text {fox }}<<t_{\text {box }}$, giving rise to $\mathrm{C}_{\mathrm{fox}}=\varepsilon_{\mathrm{ox}} / \mathrm{t}_{\mathrm{fox}}>>\mathrm{C}_{\mathrm{box}}=\varepsilon_{\mathrm{ox}} / \mathrm{t}_{\mathrm{box}}$, this would only result in a negligible additional LHS term in eq. (3). ${ }^{42)}$ This can also be seen by analyzing the expected impact on back-channel conduction due to the induced film potential $\left(\Delta \mathrm{V}_{\mathrm{bs}}\right)$ when switching off the front gate. From the amplitude of the $I_{D}$ transients measured under $V_{B G}$ conditions near $0 \mathrm{~V}$, it is found that they are generated by an effective front-gate voltage overdrive $\left(\Delta \mathrm{V}_{\mathrm{FG} \text { eff }}\right)$ in the range of $40-50 \mathrm{mV}$, which can be associated with a change in the film potential in the range of $200 \mathrm{mV}$ [Fig. $8(\mathrm{a})]^{5,40)}$

$$
\Delta \mathrm{V}_{\mathrm{FG} \mathrm{eff}} \approx-\Delta \mathrm{V}_{\mathrm{bs}} \frac{\mathrm{C}_{\mathrm{wf}}}{\mathrm{C}_{\mathrm{fox}}}
$$


Here, $\mathrm{C}_{\mathrm{wf}}=\varepsilon_{\mathrm{Si}} / \mathrm{w}_{\mathrm{f}}$ and $\mathrm{C}_{\text {fox }}=\varepsilon_{\mathrm{ox}} / \mathrm{t}_{\text {fox }}$ are the front-channel depletion and front-gate oxide capacitance densities, respectively; $\varepsilon_{\mathrm{Si}}$ and $\varepsilon_{\mathrm{ox}}$ are the corresponding permittivities and $\mathrm{w}_{\mathrm{f}}$ is the front channel depletion width $\left[\mathrm{w}_{\mathrm{f}}\left(\right.\right.$ at $\left.\left.\left.\mathrm{V}_{\mathrm{FG}}=0.1 \mathrm{~V}\right) \approx 42 \mathrm{~nm}\right)\right]$. These results are in agreement with the estimated induced $\Delta \mathrm{V}_{\text {bs }}$ values when taking into account the depletion widths corresponding to $\mathrm{V}_{\mathrm{FG}}=0.7 \mathrm{~V}$ and $\mathrm{V}_{\mathrm{FG}}=0.1 \mathrm{~V}$ conditions, as extracted from $\mathrm{C}-\mathrm{V}$ measurements on MOS capacitors fabricated with the same process but on bulk wafers. ${ }^{40)}$

Based on the above $\Delta \mathrm{V}_{\mathrm{bs}}$ values induced when switching off the front gate, one may estimate the effective back-gate voltage overdrive $\left(\Delta \mathrm{V}_{\mathrm{BG} \text { eff }}\right)$ according to [Fig. $\left.8(\mathrm{a})\right]^{5)}$

$$
\Delta \mathrm{V}_{\mathrm{BG} \mathrm{eff}} \approx-\Delta \mathrm{V}_{\mathrm{bs}} \frac{\mathrm{C}_{\mathrm{wb}}}{\mathrm{C}_{\mathrm{box}}}
$$

Here, $\mathrm{C}_{\mathrm{wb}}=\varepsilon_{\mathrm{Si}} / \mathrm{w}_{\mathrm{b}}$ and $\mathrm{C}_{\mathrm{box}}=\varepsilon_{\mathrm{ox}} / \mathrm{t}_{\mathrm{box}}$ are the back-channel depletion and back-gate oxide capacitance densities, respectively.

According to eq. (5), an $\Delta \mathrm{V}_{\mathrm{BG}}$ eff value in the range of $10 \mathrm{~V}$ would be expected for these PD SOI devices, which is, of course, not observed. Moreover, if $\Delta \mathrm{V}_{\mathrm{bs}}$ was introducing important changes in the whole back channel depletion width, i.e., in the neutral film width, one should also expect significant changes in the second $g_{m}$ peak of the $I_{D}-V_{F G}$ characteristics measured at different $V_{B G}$ values, as well as on the amplitude of the $I_{D}$ transients. ${ }^{43}$

Taking into account the fact that the back-channel leakage is associated with a parasitic conduction along the edges between the buried oxide and the PELOX field isolation, it has been shown by device simulation that under the presence of positive trapped charges in either the field isolation edge or the buried oxide, a narrow region close to the field isolation 
edge operates in the fully depleted mode, giving rise to coupling between the front and back gates (Fig. 8(b)). ${ }^{27,29)}$ This is also in agreement with the $\mathrm{V}_{\mathrm{Tb}}$ behavior observed in narrow channel devices, in which the regions close to the PELOX isolation become dominant. ${ }^{32)}$

Under these circumstances, the relevant coupling factor for the parasitic back-channel conduction is dictated by the $\mathrm{C}_{\mathrm{eq}}$ capacitance. ${ }^{5,50)}$

$$
\mathrm{C}_{\mathrm{eq}}=\frac{\mathrm{C}_{\mathrm{fox}} \cdot \mathrm{C}_{\mathrm{si}}}{\mathrm{C}_{\mathrm{fox}}+\mathrm{C}_{\mathrm{si}}}
$$

Here, $\mathrm{C}_{\mathrm{si}}=\varepsilon_{\mathrm{si}} / \mathrm{t}_{\mathrm{si}}$ is the silicon film capacitance density.

Taking into account $\mathrm{C}_{\mathrm{eq}}$, the effective back gate voltage overdrive values ( $\Delta \mathrm{V}_{\mathrm{BG}}$ eff $)$ when switching off the front gate can be estimated from eq. (7) [Fig. 8(b)].

$$
\Delta \mathrm{V}_{\mathrm{BG} \mathrm{eff}} \approx-\Delta \mathrm{V}_{\mathrm{FG} \mathrm{eff}} \frac{\mathrm{C}_{\mathrm{eq}}}{\mathrm{C}_{\mathrm{box}}}
$$

Following this approach, the step in the $I_{D}$ current transients amplitude $\left[I_{D}(t=0)\right.$ $I_{D}(t=\infty)$ ] as a function of $V_{B G}$ (Fig. 7) can be explained by the onset of the back-channel parasitic current transient component, which is added to the conventional front-gate $\mathrm{I}_{\mathrm{D}}$ transient. The $\mathrm{V}_{\mathrm{BG}}$ position of the step in the transients amplitude is shifted after irradiation according to the shift in the $\mathrm{I}_{\mathrm{D}}-\mathrm{V}_{\mathrm{BG}}$ characteristics $\left(\Delta \mathrm{V}_{\mathrm{Tb}}\right)$. The magnitude of this backchannel contribution to the $I_{D}$ transients amplitude at the different $V_{B G}$ biases can be easily extracted from the estimated $\Delta \mathrm{V}_{\mathrm{BG} \text { eff }}$ [eq. (7)] and the measured $\mathrm{I}_{\mathrm{D}^{-}} \mathrm{V}_{\mathrm{BG}}$ characteristics (Fig. 7), being these results in good agreement with the measured $I_{D}(t=0)-I_{D}(t=\infty)$ data in Fig. 7. 


\section{Conclusions}

The impact of back-channel radiation-induced leakage and back-gate bias on switchoff $I_{D}$ transients of thin gate oxide PD SOI nMOSFETs has been analyzed. The presence of radiation-induced positive trapped charges in the buried oxide after $60 \mathrm{MeV}$ proton irradiation has been found to reduce the "switch-off" $I_{D}$ transient times for $V_{F G}$ values above and below the threshold voltage for body-to-gate EVB tunnelling. An increase in steady state $I_{D}$ and an increase in the amplitude of the weak inversion $I_{D}$ transients has been found. A similar effect has been observed when applying a positive $\mathrm{V}_{\mathrm{BG}}$, which has been found to generate an "irradiation-like" subthreshold leakage. The observed $\mathrm{I}_{\mathrm{D}}$ transient behavior is explained by taking into account an edge parasitic back-channel transient component, which is added to the conventional front-gate $I_{D}$ transient.

\section{Acknowledgements}

J.M. Rafí acknowledges the European Commission for his postdoctoral Marie Curie Fellowship. Dr. Hans van Meer and Professor Kristin De Meyer are warmly thanked for providing the devices and the relevant process information. Guy Berger and his colleagues of Centre de Recherches du Cyclotron, Louvain-la-Neuve, Belgium, are gratefully acknowledged for their assistance during the $60 \mathrm{MeV}$ proton irradiations. 


\section{REFERENCES}

1) T. P. Ma and P. V. Dressendorfer: Ionizing Radiation Effects in MOS Devices and Circuits (John Wiley \& Sons, New York, 1989).

2) C. Claeys and E. Simoen: Radiation Effects in Advanced Semiconductor Materials and Devices (Springer, Berlin, 2002).

3) J. R. Schwank, V. Ferlet-Cavrois, M. R. Shaneyfelt, P. Paillet and P. E. Dodd: IEEE Trans. Nucl. Sci. 50 (2003) 522.

4) S. Cristoloveanu and S. S. Li: Electrical Characterization of Silicon-On-Insulator Materials and Devices. (Kluwer Academic Publishers, Boston, 1995).

5) J.-P. Colinge: Silicon-On-Insulator Technology: Materials to VLSI (Kluwer Academic Publishers, Boston, 1997) 2nd ed.

6) S. S. Eaton and B. Lalevic: IEEE Trans. Electron Devices 25 (1978) 907.

7) H. K. Lim and J. G. Fossum: IEEE Trans. Electron Devices 31 (1984) 1251.

8) P. W. Barth and J. B. Angell: IEEE Trans. Electron Devices 27 (1980) 2252.

9) D. E. Ioannou, S. Cristoloveanu, M. Mukherjee and B. Mazhari: IEEE Electron Device Lett. 11 (1990) 409.

10) N. Yasuda, K. Taniguchi, C. Hamaguchi, Y. Yamaguchi and T. Nishimura: IEEE Trans. Electron Devices 39 (1992) 1197.

11) D. Kimpton and J. Kerr: IEEE Trans. Nucl. Sci. 39 (1992) 2126.

12) D. Munteanu, D. A. Weiser, S. Cristoloveanu, O. Faynot, J.-L. Pelloie and J. G. Fossum: IEEE Trans. Electron Devices 45 (1998) 1678.

13) H. Shin, M. Racanelli, W. M. Huang, J. Foerstner, T. Hwang and D. K. Schroder: SolidState Electron. 43 (1999) 349.

14) D. Munteanu and A.-M. Ionescu: IEEE Trans. Electron Devices 49 (2002) 1198.

15) W. C. Lee and C. Hu: IEEE Trans. Electron Devices 48 (2001) 1366.

16) J. Pretet, T. Matsumoto, T. Poiroux, S. Cristoloveanu, R. Gwoziecki, C. Raynaud, A. Roveda and H. Brut: Proceedings of ESSDERC, 2002, p. 515.

17) A. Mercha, J. M. Rafí, E. Simoen, E. Augendre and C. Claeys: IEEE Trans. Electron Devices 50 (2003) 1675. 
18) F. Dieudonné, J. Jomaah and F. Balestra: IEEE Electron Device Lett. 23 (2002) 737.

19) A. Mercha, E. Simoen, H. van Meer and C. Claeys: Appl. Phys. Lett. 82 (2003) 1790.

20) T. Poiroux, O. Faynot, C. Tabone, H. Tigelaar, H. Mogul, N. Bresson, S. Cristoloveanu: Proc. IEEE Int. SOI Conf., 2002, p. 99.

21) J.-W. Yang, J. G. Fossum, G. O. Workman and C. L. Huang: Solid-State Electron. 48 (2004) 259.

22) B. Y. Tsaur, J. C. C. Fan, G. W. Turner and D. J. Silversmith: IEEE Electron Device Lett. 3 (1982) 195.

23) J. R. Schwank, M. R. Shaneyfelt, P. E. Dodd, V. Ferlet-Cavrois, R. A. Loemker, P. S. Winokur, D. M. Fleetwood, P. Paillet, J.-L. Leray, B. L. Draper, S. C. Witczak and L. C. Riewe: IEEE Trans. Nucl. Sci. 47 (2000) 2175.

24) S. T. Liu, W. C. Jenkins and H. L. Hughes: Proc. of 9th Int. Symp. Silicon-on-Insulator Technology and Devices, The Electrochemical Society PV 99-3, 1999, p. 225.

25) V. Ferlet-Cavrois, O. Musseau, J.-L. Leray, J.-L. Pelloie and C. Raynaud: IEEE Trans. Electron Devices 44 (1997) 965.

26) D. C. Mayer: IEEE Trans. Electron Devices 37 (1990) 1280.

27) A. Yasuoka, T. Iwamatsu, T. Ipposhi, S. Miyamoto, Y. Yamaguchi, Y. Inoue and H. Miyoshi: Jpn. J. Appl. Phys. 36 (1997) 1631.

28) Y. Hirano, S. Maeda, W. Fernandez, T. Iwamatsu, Y. Yamaguchi, S. Maegawa and T. Nishimura: Jpn. J. Appl. Phys. 38 (1999) 2487.

29) M. Haond and O. Le Neel: Solid-State Technol. 34 (1991) 47.

30) K. Hayama, K. Takakura, H. Ohyama, M. Kokkoris, J. M. Rafí, A. Mercha, E. Simoen and C. Claeys: Accepted to be presented at NSREC, 2004.

31) J. R. Schwank: Microelectron. Eng. 36 (1997) 335.

32) J. M. Rafí, A. Mercha, E. Simoen, C. Claeys and A. Mohammadzadeh: To be published in Proceedings of RADECS, 2003.

33) E. Simoen, J. M. Rafí, A. Mercha and C. Claeys: Solid-State Electron. 48 (2004) 1045.

34) J. Chen, T. Y. Chan, I. C. Chen, P. K. Ko and C. Hu: IEEE Electron Device Lett. 8 (1987) 515. 
35) M. J. Sherony, I. Y. Yang, D. A. Antoniadis and B. S. Doyle: Proc. IEEE Int. SOI Conf., 1996, p. 84.

36) G. U. Youk, P. S. Khare, R. D. Schrimpf, L. W. Massengill and K. F. Galloway: IEEE Trans. Nucl. Sci. 46 (1999) 1830.

37) M. R. Shaneyfelt, P. E. Dodd, B. L. Draper and R. S. Flores: IEEE Trans. Nucl. Sci. 45 (1998) 2584.

38) J. M. Rafí, A. Mercha, E. Simoen, X. Serra-Gallifa and C. Claeys: Proc. 4th Conferencia de Dispositivos Electrónicos CDE, 2003, p. V-12.

39) A. M. Ionescu, D. Munteanu, N. Hefyene and C. Anghel: J. Electrochem. Soc. 151 (2004) G396.

40) J. M. Rafí, A. Mercha, E. Simoen and C. Claeys: Solid-State Electron. 48 (2004) 1211.

41) D. K. Schroder: IEEE Trans. Electron Devices 44 (1997) 160.

42) A. Ionescu and S. Cristoloveanu: Nucl. Instrum. \& Methods B 84 (1994) 265.

43) A. M. Ionescu, A. Rusu and A. Chovet: Microelectron. Eng. 28 (1995) 431.

44) A. M. Ionescu, A. Rusu, A. Chovet and S. Cristoloveanu: Proc. of ESSDERC, 1994, p. 783.

45) H. C. Shin, I.-S. Lim, M. Racanelli, W.-L. M. Huang, J. Foerstner and B.-Y. Hwang: IEEE Trans. Electron Devices 43 (1996) 318.

46) T. Saraya, M. Takamiya, T. N. Duyet and T. Hiramoto: Jpn. J. Appl. Phys. 37 (1998) 1271.

47) S. Cristoloveanu, A.M. Ionescu, A. Chovet, E. H. M. Heijne and P. Jarron: Proc. of RADECS, 1993, p. 385.

48) D. P. Vu and J. C. Pfister: Appl. Phys. Lett. 47 (1985) 950.

49) A. M. Ionescu and A. Chovet: Microelectron. Eng. 48 (1999) 371.

50) T. Ouisse, S. Cristoloveanu and G. Borel: Solid-State Electron. 35 (1992) 141. 


\section{FIGURE CAPTIONS}

Fig. 1: (a) $I_{D}$ and corresponding $g_{m}$ versus $V_{F G}$ characteristics measured at $V_{B G}=0 \mathrm{~V}$ and $\mathrm{V}_{\mathrm{BG}}=-20 \mathrm{~V}$ for an irradiated $\mathrm{L}=\mathrm{W}=10 \mu \mathrm{m}$ nMOSFET (after $2 \times 10^{11}$ protons $/ \mathrm{cm}^{2}$ ) and for a nonirradiated one measured at different positive and negative $V_{B G}$ values. (b) $I_{D}$ and corresponding $g_{m}$ versus $V_{F G}$ characteristics measured at $\mathrm{V}_{\mathrm{BG}}=0$ for an $\mathrm{L}=\mathrm{W}=10 \mu \mathrm{m}$ pMOSFET before and after $2 \times 10^{11}$ protons $/ \mathrm{cm}^{2}$ irradiation.

Fig. 2: (a) Normalized "switch-off" $I_{D}$ transients measured at $V_{B G}=0 \mathrm{~V}$ on a $L=W=$ $10 \mu \mathrm{m}$ nMOSFET before and after $10^{11}$ protons $/ \mathrm{cm}^{2}$ irradiation, together with the results obtained for a nonirradiated one measured at $\mathrm{V}_{\mathrm{BG}}=14 \mathrm{~V}$. (b) Normalized switch-off $\mathrm{I}_{\mathrm{D}}$ transients measured at $\mathrm{V}_{\mathrm{BG}}=0 \mathrm{~V}$ on a $\mathrm{L}=\mathrm{W}=10 \mu \mathrm{m}$ pMOSFET before and after $10^{11}$ protons $/ \mathrm{cm}^{2}$ irradiation.

Fig. 3: Plot for effective generation lifetime $\left(\tau_{\text {geff }}\right)$ extraction based on eq. (3) method (LHS-RHS). The different curves correspond to the data from "switch-off" (from $\mathrm{V}_{\mathrm{FG} \text { on }}=0.7 \mathrm{~V}$ to $\mathrm{V}_{\mathrm{FG} \text { off }}=0.1 \mathrm{~V}$ ) $\mathrm{I}_{\mathrm{D}}$ transients measured for an $\mathrm{L}=\mathrm{W}=10$ $\mu \mathrm{m}$ nMOSFET biased at different $\mathrm{V}_{\mathrm{D}}$ values. The corresponding $\tau_{\text {geff }}$ extracted values are shown as functions of $1 / \mathrm{V}_{\mathrm{D}}$ in the inset, together with the ones extracted using eq. (1) ( $\left.\mathrm{T}_{0} 90 \%\right)$.

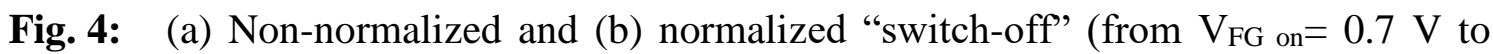
$\left.\mathrm{V}_{\mathrm{FG} \text { off }}=0.1 \mathrm{~V}\right) \mathrm{I}_{\mathrm{D}}$ transients measured at different $\mathrm{V}_{\mathrm{BG}}$ conditions for a nonirradiated $\mathrm{L}=\mathrm{W}=10 \mu \mathrm{m}$ nMOSFET. 
Fig. 5: Measured $I_{D}$ transient times (defined as the time to reach either, $90 \%$ (undershoot) or $110 \%$ (overshoot) of $\mathrm{I}_{\mathrm{D}}(\mathrm{t}=\infty)$ ) versus $\mathrm{V}_{\mathrm{BG}}$ for irradiated and nonirradiated $\mathrm{L}=\mathrm{W}=10 \mu \mathrm{m}$ nMOSFETs after switching off their front gate from $\mathrm{V}_{\mathrm{FG} \text { on }}=0.7 \mathrm{~V}$ to $\mathrm{V}_{\mathrm{FG} \text { off }}=0.1 \mathrm{~V}$ and from $\mathrm{V}_{\mathrm{FG} \text { on }}=1.5 \mathrm{~V}$ to $\mathrm{V}_{\mathrm{FG} \text { off }}=0.1 \mathrm{~V}$.

Fig. 6: Plot for effective generation lifetime ( $\left.\tau_{\text {geff }}\right)$ extraction based on eq. (3). The different curves correspond to the data from "switch-off" (from $V_{F G}$ on $=0.7 \mathrm{~V}$ to $\mathrm{V}_{\mathrm{FG} \text { off }}=0.1 \mathrm{~V}$ ) $\mathrm{I}_{\mathrm{D}}$ transients measured for (a) irradiated and (b) nonirradiated $\mathrm{L}=\mathrm{W}=10 \mu \mathrm{m}$ nMOSFETs at different $\mathrm{V}_{\mathrm{BG}}$ values.

Fig. 7: Amplitude $\left(\mathrm{I}_{\mathrm{D}}(\mathrm{t}=0 \mathrm{~s})-\mathrm{I}_{\mathrm{D}}(\mathrm{t}=\infty)\right)$ of "switch-off" $\left(\mathrm{V}_{\mathrm{FG} \text { on }}=0.7 \mathrm{~V}\right.$ to $\mathrm{V}_{\mathrm{FG} \text { off }}=0.1$ V) $I_{D}$ transients measured for irradiated and nonirradiated $L=W=10 \mu \mathrm{m}$ nMOSFETs at different $V_{B G}$ biases. The corresponding $I_{D}$ vs. $V_{B G}$ characteristics measured at $\mathrm{V}_{\mathrm{FG}}=0 \mathrm{~V}$ are also given and the quantitative effects associated with the back-channel component (extra back gate bias, eq. 7) are also indicated.

Fig. 8: Schematic representation of the impact of a switch-off-induced film potential $\left(\Delta \mathrm{V}_{\mathrm{bs}}\right)$ on the front- and back-gate voltage overdrives $\left(\Delta \mathrm{V}_{\mathrm{FG}}\right.$ eff and $\Delta \mathrm{V}_{\mathrm{BG} \text { eff, }}$ respectively) through the involved capacitances. (a) Nonirradiated PD SOI nMOSFET case. (b) Irradiated PD SOI nMOSFET or nonirradiated one measured at sufficiently positive $\mathrm{V}_{\mathrm{BG}}$, giving rise to back-channel edge leakage current and full depletion near the field isolation edges. 


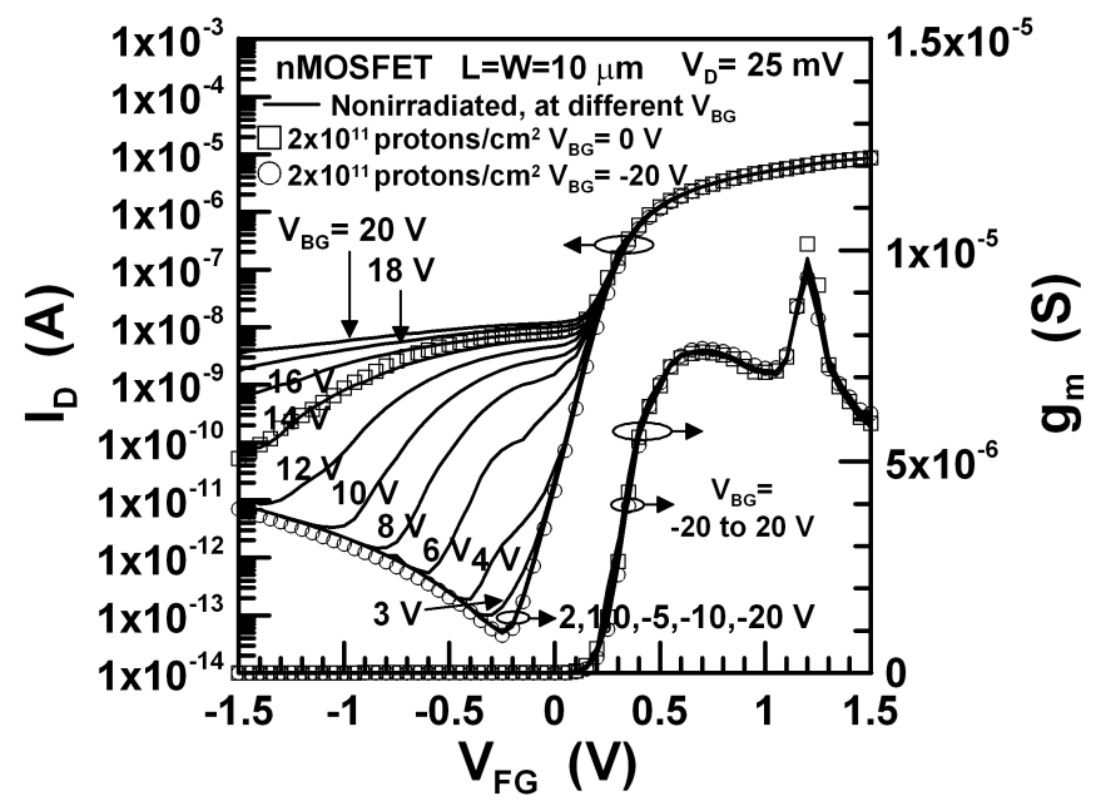

Fig. 1(a)

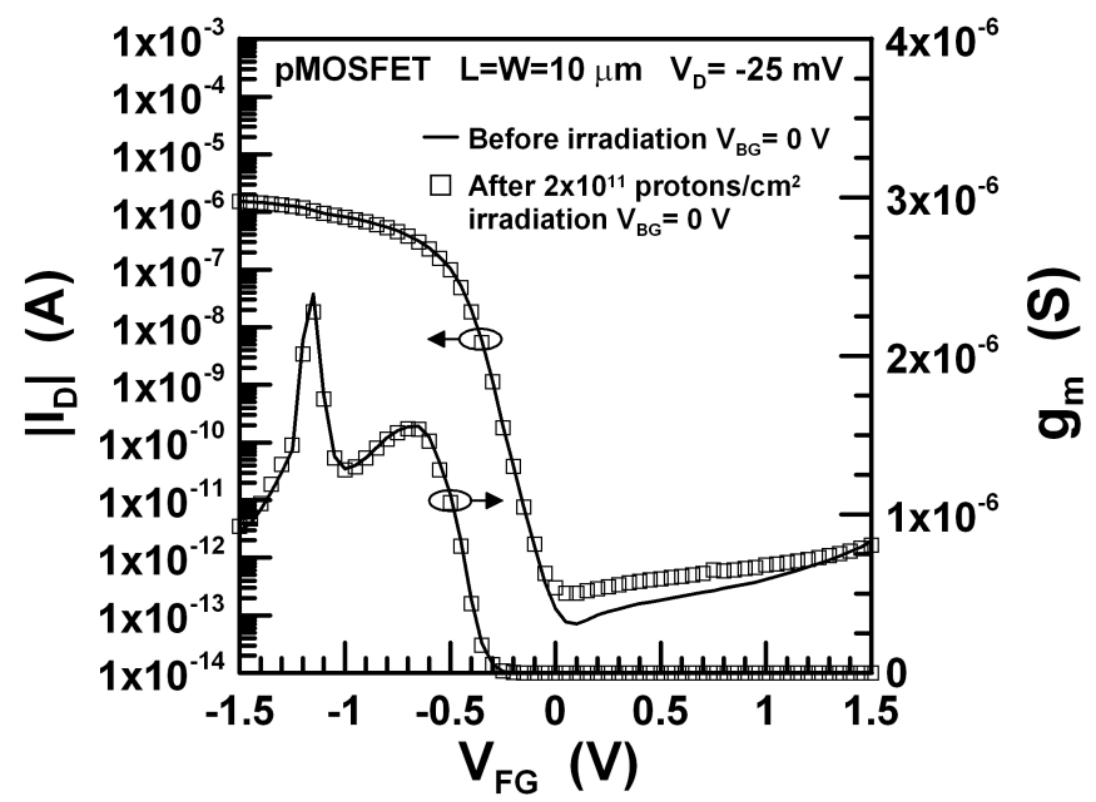

Fig. 1(b) 


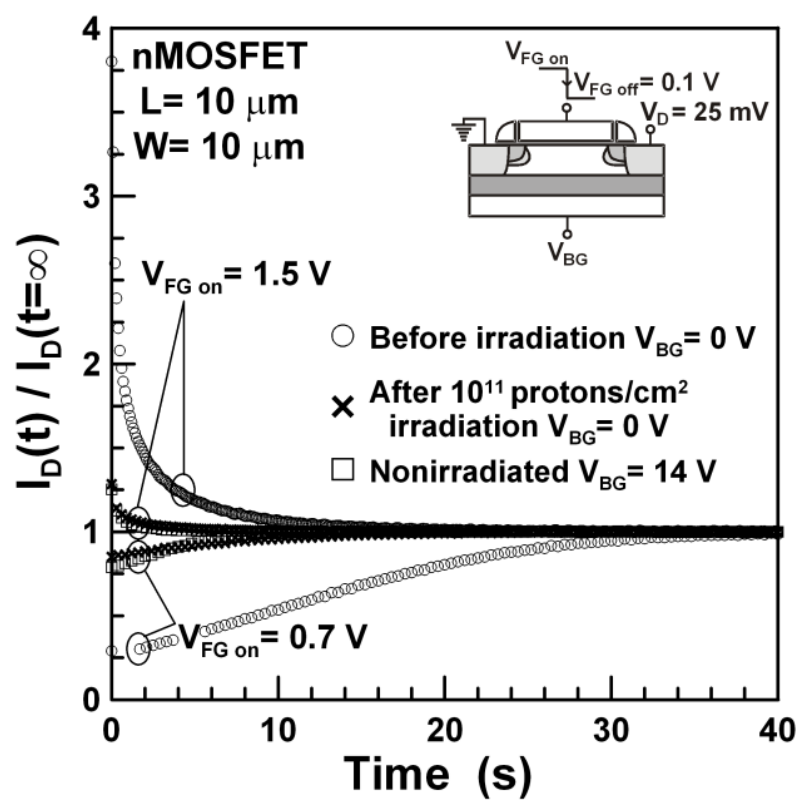

Fig. 2(a)

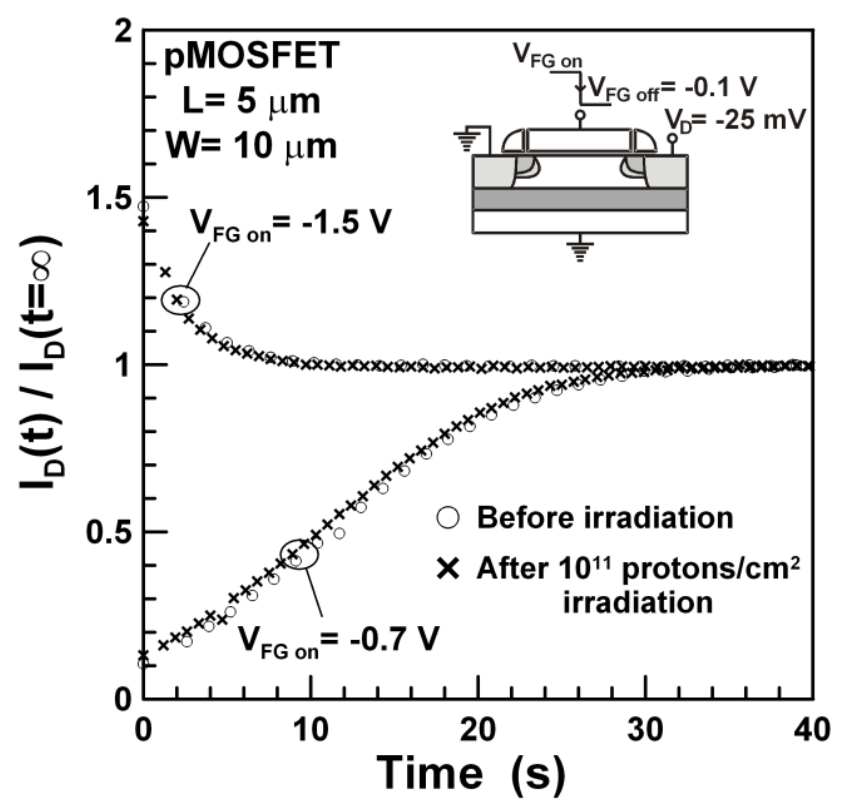

Fig. 2(b) 


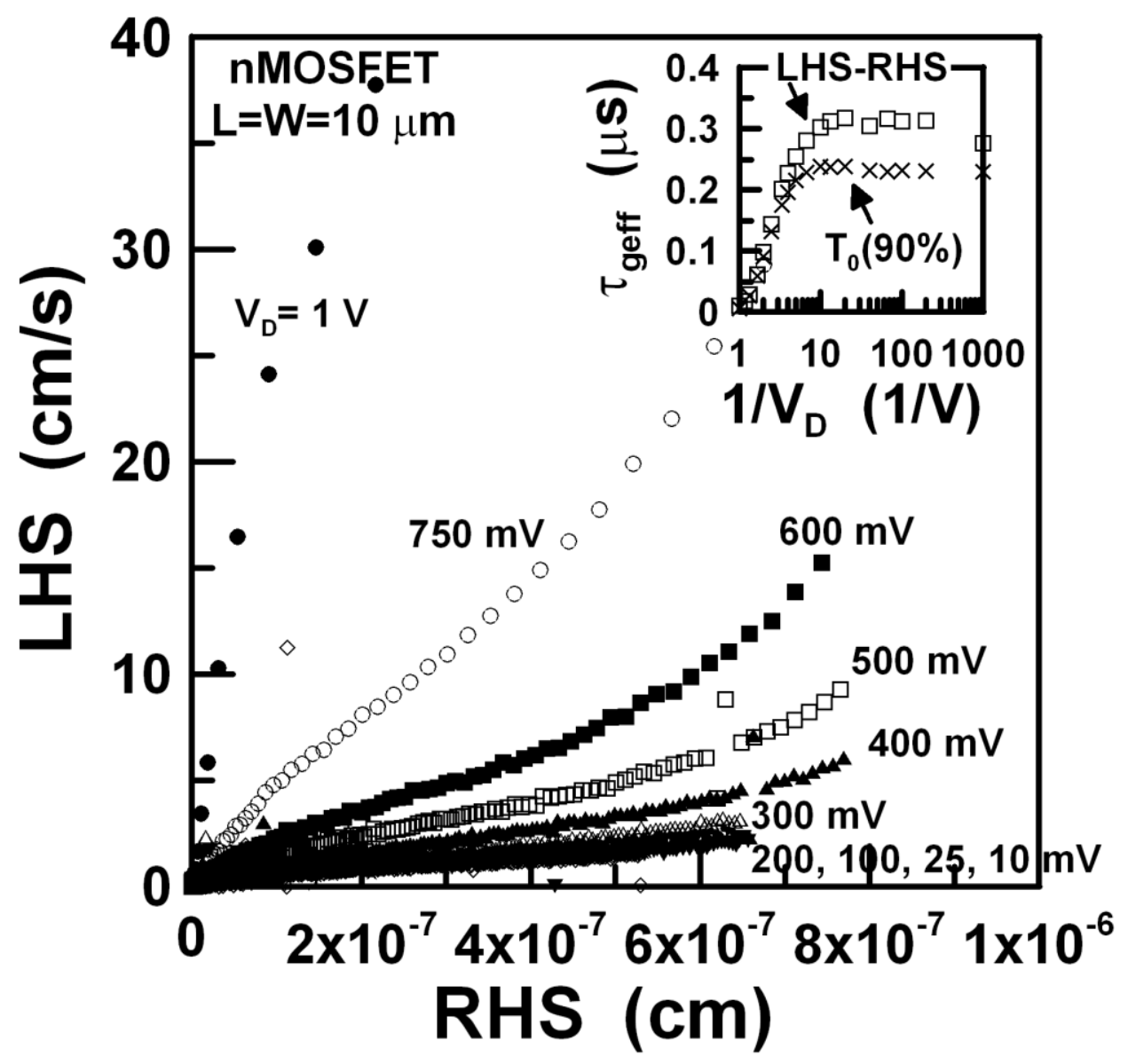

Fig. 3 


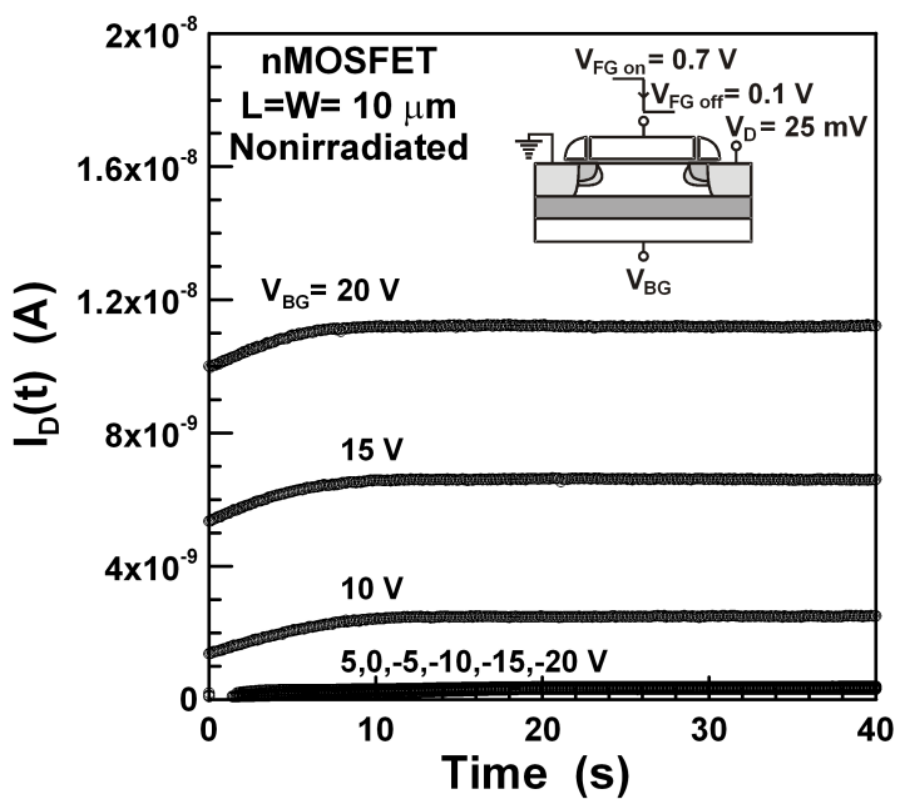

Fig. 4(a)

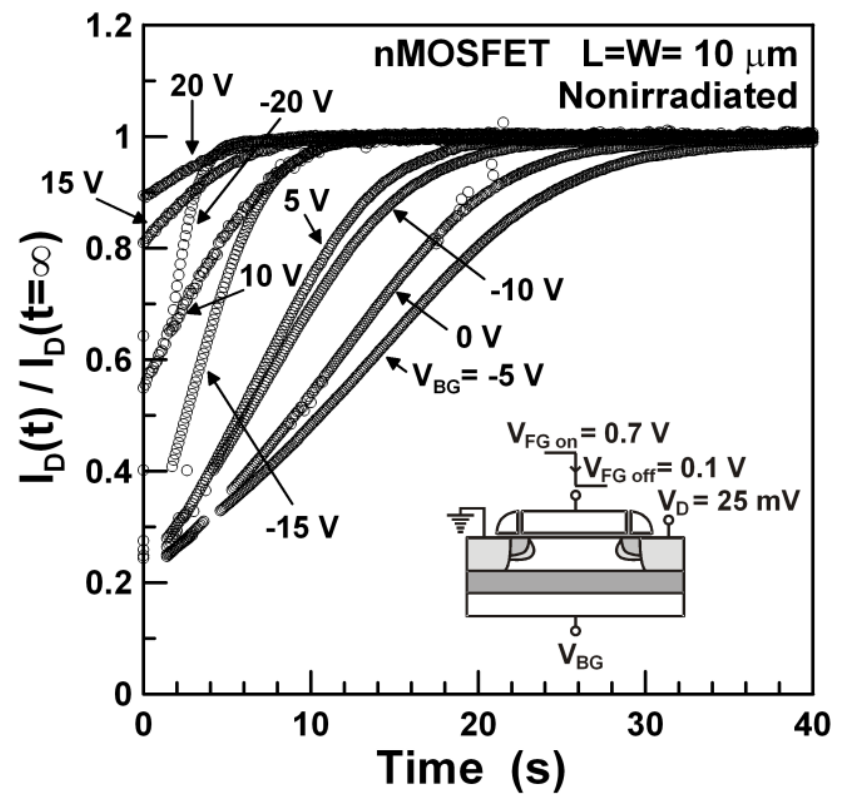

Fig. 4(b) 


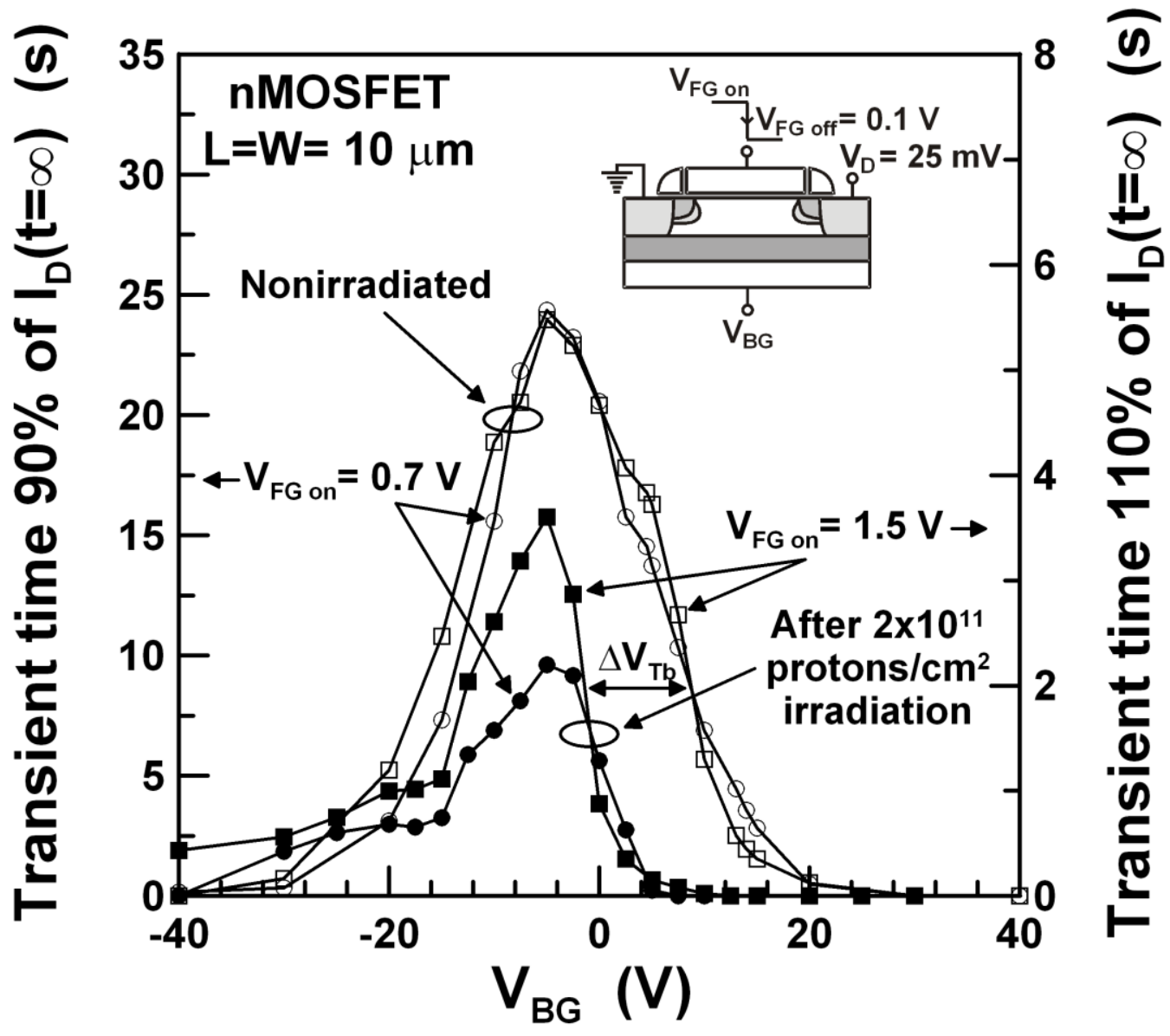

Fig. 5 


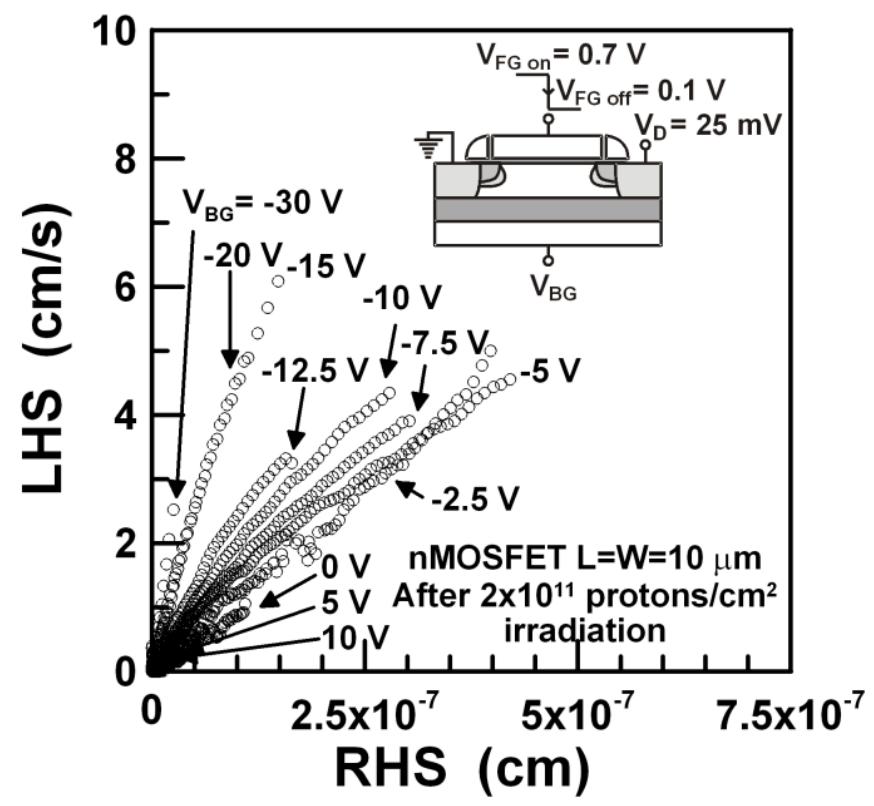

Fig. 6(a)

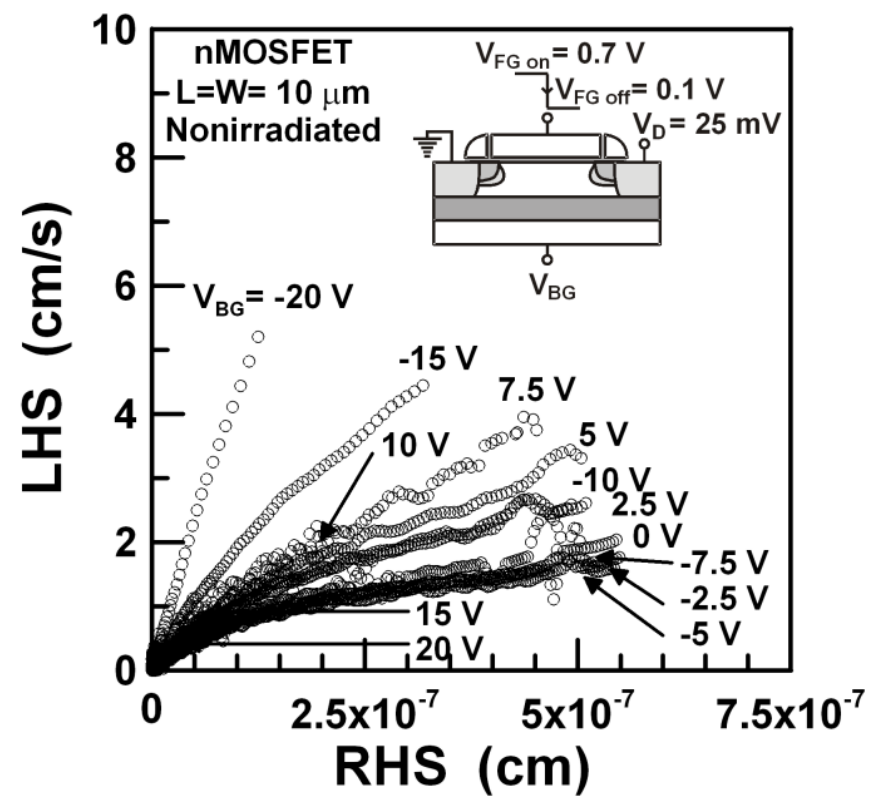

Fig. 6(b) 


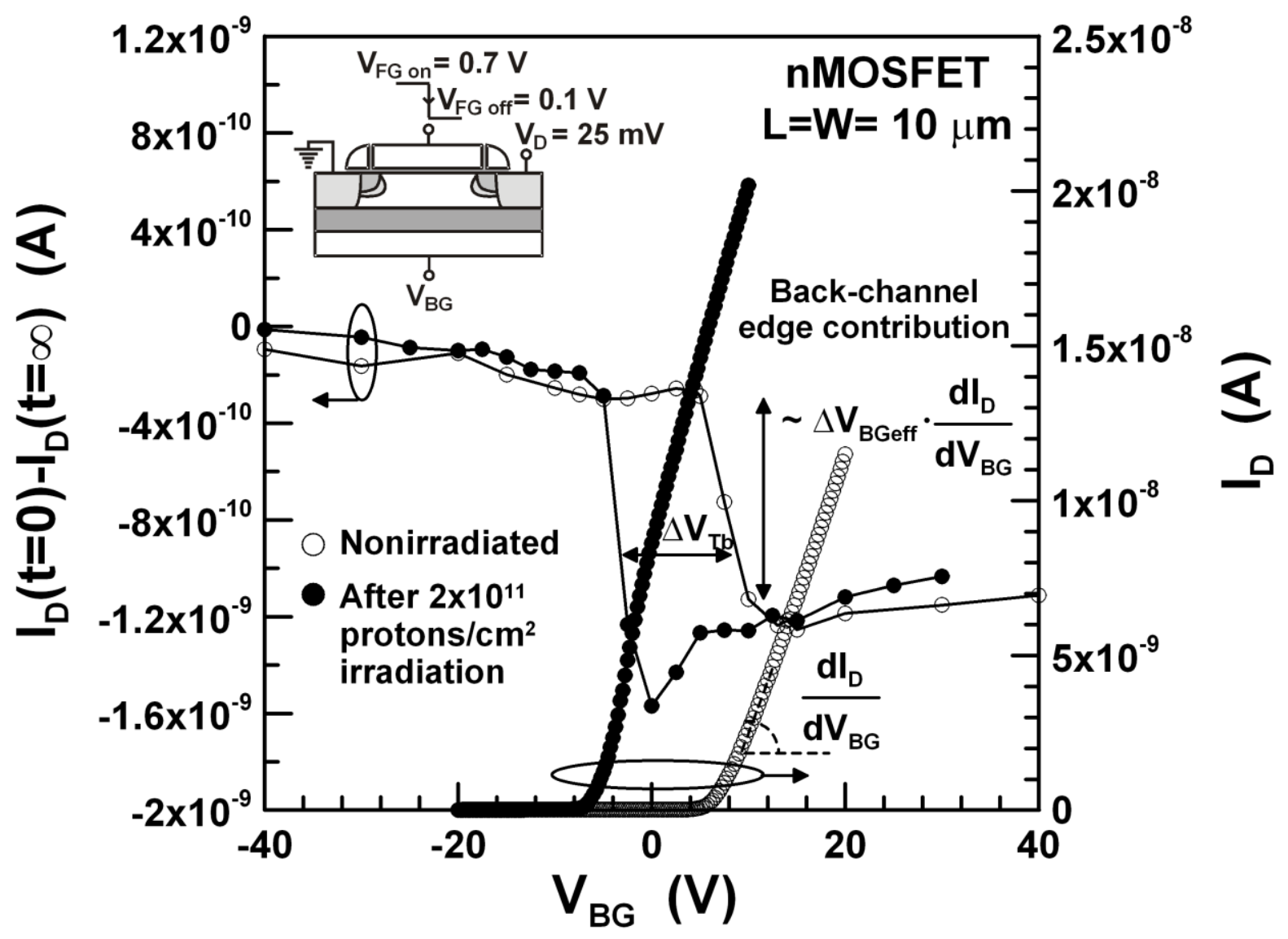

Fig. 7 


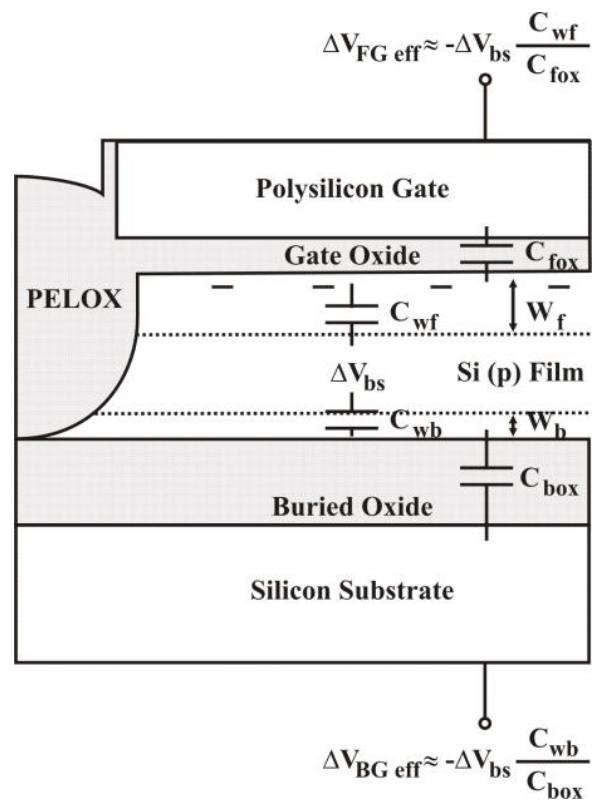

Fig. 8(a)

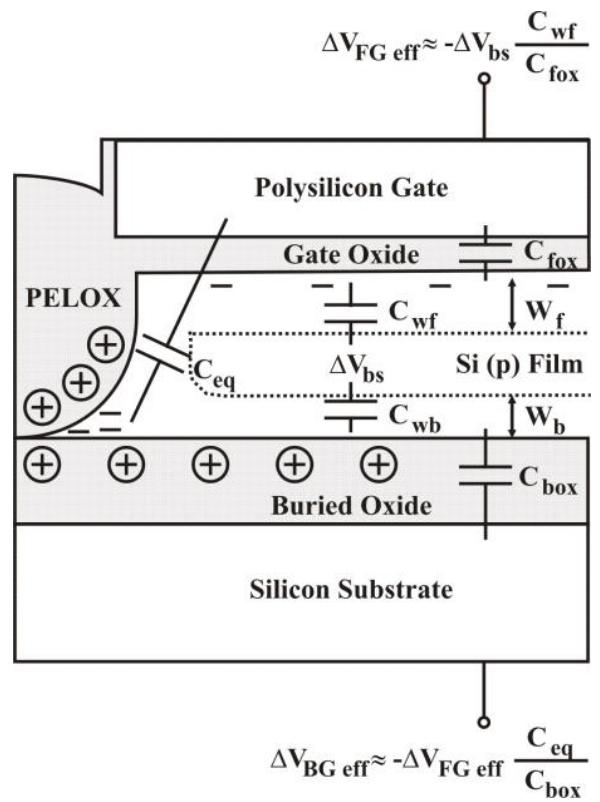

Fig. 8(b) 